\title{
Transient Hemifacial Sensory Loss with Xerophthalmia following Temporal Lobectomy
}

\author{
Ajith J. Thomas, Kost Elisevich and Brien Smith
}

\begin{abstract}
Objective and importance: The occurrence of a unilateral sensory loss in the second trigeminal distribution and the inability to tear following an ipsilateral temporal lobectomy has not been noted despite a number of reports of cranial nerve compromise under similar situations. Clinical presentation: A 48-year-old woman experienced complex partial seizures over three years attributable to the presence of cavernous malformations of the right temporal lobe. Intervention: An anterior temporal extrahippocampal resection was performed. The surgery was marked by the need for electrocoagulation of the dural base of the temporal lobe where numerous bleeding points were encountered. Postoperatively, the patient experienced an ipsilateral maxillary division sensory loss, absence of tearing, and diminished nasal congestion for an eight-month period until resolution. Conclusion: Injury of the fibers of the maxillary division of the trigeminal nerve and the adjacent greater superficial petrosal nerve appears to be the cause. No prior account of such an occurrence has been published.
\end{abstract}

\begin{abstract}
RÉSUMÉ: Perte sensitive hémifaciale transitoire avec xérophthalmie suite à une lobectomie temporale. Objectif et importance: La perte de sensibilité unilatérale dans le territoire de la deuxième branche du trijumeau et l'absence de larmes suite à une lobectomie temporale ipsilatérale n'a pas été notée bien que plusieurs rapports font état d'atteintes de nerfs crâniens dans des circonstances analogues. Présentation clinique: Une femme âgée de 48 ans a présenté pendant 3 ans des crises complexes partielles dues à la présence de malformations caverneuses du lobe temporal droit. Intervention: Une résection temporale antérieure extrahippocampale a été effectuée. La chirurgie a nécessité l'électrocoagulation de plusieurs vaisseaux à la base durale du lobe temporal. En postopératoire, la patiente a présenté pendant de 8 mois une perte sensitive dans le territoire maxillaire ipsilatéral, une absence de larmes et une diminution de la congestion nasale. Conclusion: Une lésion des fibres de la branche maxillaire du trijumeau et du grand nerf pétreux superficiel adjacent semble être la cause de cette complication qui n'a jamais été rapportée.
\end{abstract}

Can. J. Neurol. Sci. 2000; 27: 251-253

Anterior temporal lobectomy, including amygdalohippocampectomy for epilepsy, may result in a variety of neurologic deficits attributable to the resection of the temporal lobe, direct injury to neighboring structures, traction of extratemporal tissues, or vascular compromise. Certain extra-axial cranial nerve injuries have been specifically documented with amygdalohippocampectomy. Transient dysfunction of the third cranial nerve has been reported in up to $15 \%$ of patients, ${ }^{1-4}$ whereas a permanent dysfunction has been noted in isolated cases in some series. ${ }^{5-7}$ Fourth cranial nerve dysfunction has been less frequently reported, ${ }^{5,8}$ and transient seventh cranial nerve dysfunction has also been mentioned. ${ }^{9,10}$

We conducted a review of our series of temporal lobectomies performed for the treatment of epilepsy to determine the frequency of cranial neuropathy, both transient and persistent, sustained from surgery. We found one instance of persistent partial oculomotor nerve dysfunction, two cases of transient trochlear nerve paresis, and a single instance of unilateral xerophthalmia with sensory loss in the distribution of the maxillary division of the trigeminal nerve. The latter case identifies a hitherto unreported outcome of temporal lobectomy following the removal of two cavernous malformations and the surrounding epileptogenic temporal lobe. This report will identify the nature of a distinctive postoperative neurologic deficit and propose the manner by which it occurred.

From the Departments of Neurosurgery (AJT, KE) and Neurology (BS), Henry Ford Hospital, Detroit, Michigan.

ReCeived DeCEMBer 2, 1999. ACCEPTED IN FinAl FORM MAY 9, 2000.

Reprint requests to: Kost Elisevich, Department of Neurosurgery, c/o Editorial Office, Henry Ford Hospital, 2799 West Grand Boulevard, Detroit, MI 48202 USA. 


\section{Patients And Methods}

A review of extra-axial cranial neuropathies in 204 cases of partial temporal lobectomy performed for the treatment of medically intractable epilepsy from June 1993 through April 1999 yielded a single case in which a unilateral absence of tearing and sensory loss to pinprick and light touch in the midfacial distribution were noted following surgery.

\section{Case description.}

A 48-year-old woman presented with a complex partial seizure disorder of three years duration manifesting as a deja $v u$ episode followed by a "rushing sensation" from the midabdomen to the face. The episodes were brief but occurred as frequently as 30 times daily, often awakening her from sleep. She had no neurologic deficits on examination. Magnetic resonance imaging identified two lesions measuring $12 \times 5 \mathrm{~mm}$ and $5 \times 5 \mathrm{~mm}$ appearing with high signal intensity on T2-weighted images and surrounded by a rim of low signal intensity on T1-weighted images. These were confined to the anterior, mid, and basal portions of the right temporal lobe excluding the region of the amygdala and hippocampus (Figure). Scalp and sphenoidal electroencephalogram recorded both interictal epileptiform activity and focal ictal onset over the right temporal lobe (T4 maximum).

At surgery, an area of discoloration was visible within the second temporal gyrus. Electrocorticography revealed spike activity over the cerebral convexity and basally. An en bloc resection of tissue included a posterior margin that extended medially beyond the collateral sulcus to include a small volume of parahippocampal tissue along its base. Dural hemostasis along the floor of the middle fossa was obtained with bipolar electrocautery and tamponade with gelfoam.

Postresection electrocorticography showed no further spike activity throughout the operative bed and the neighboring area. Postoperatively, two salient features were apparent: an absence of tearing over the right eye and an area of numbness localized to the maxillary division of the ipsilateral trigeminal nerve. The patient had a chronic history of rightsided maxillary sinus and nasal congestion and noted, postoperatively, a relief from congestion and drainage on this side. Tearing returned to normal in three months, whereas facial sensation began returning over a six- to nine-month period. Audiologic examination showed a mild, rightsided conductive hearing loss with normal tympanometry. A presumptive diagnosis of otosclerosis was made with a supportive family history of the same. The stapedial reflex could not be adequately assessed. Taste function was altered in that the patient's sense of sweetness was diminished despite continued appreciation of salty, sour, and bitter tastes. This improved over a number of months along with the return of her appetite.

\section{Discussion}

The findings of ipsilateral midfacial sensory loss and xerophthalmia following temporal lobectomy are unusual and suggest compromise of both the maxillary division of the trigeminal nerve and the greater superficial petrosal nerve. The return of function over the course of several months suggests further that this was attributable to extra-axial injury with regeneration of preganglionic parasympathetic fibers after either traction or thermal injury through the use of bipolar electrocautery.

The greater superficial petrosal nerve conveys preganglionic parasympathetic secretomotor fibers to the sphenopalatine ganglion. About $70 \%$ of all visceral efferent fibers from the intermediate nerve in the $\operatorname{dog}$ and cat pass in the greater superficial petrosal nerve and the remainder are found in the chorda tympani. ${ }^{11}$ Postganglionic fibers pass within the zygomatic and lacrimal nerves to the lacrimal gland. Other secretomotor fibers pass to the mucous glands of the nasal cavity. Taste fibers from the soft palate run centrally in the greater superficial petrosal nerve. The nerve leaves the intermediate (sensory) root of the facial nerve at the geniculate ganglion and passes through the hiatus of the facial canal to enter the cranial

A
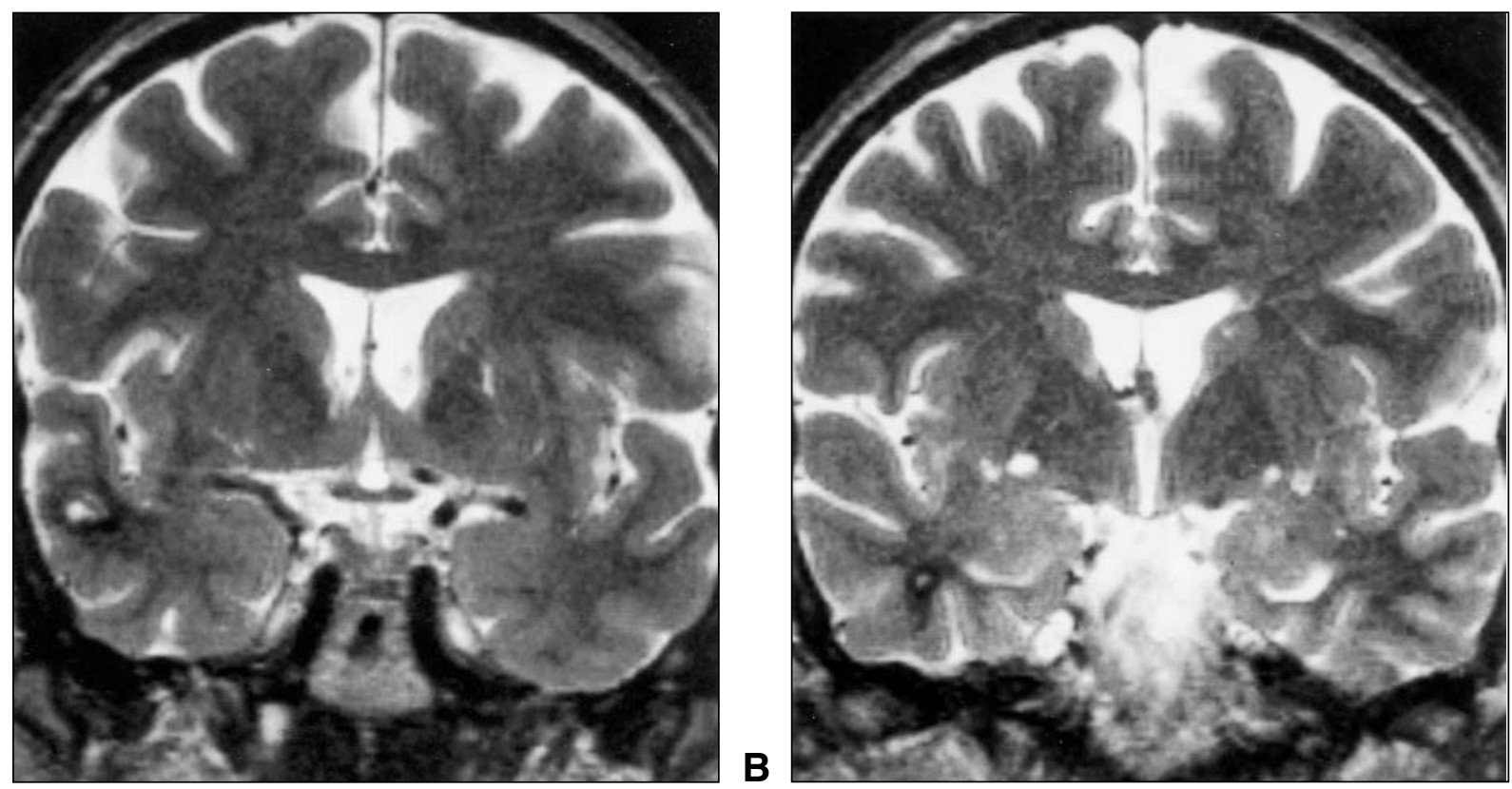

Figure: T2-weighted MR images in the coronal plane showing cavernous angiomas situated in the anterior right temporal lobe. Both are identified by their bright signal with the larger lesion found subcortically in the middle temporal gyrus (A) and the second further anteriorly in the medullary center adjacent to the region of the amygdala $(B)$. 
cavity. It runs forward and medially along the pyramid of the temporal bone to pass under the trigeminal ganglion and is therefore in close proximity to the fibers passing from the sensory root elements within the ganglion and each of the divisions of the trigeminal nerve.

Few reports identify facial nerve injury as a complication of temporal lobectomy. ${ }^{9,10}$ Facial nerve injury was reported more often in the past with subtemporal rhizotomies for trigeminal neuralgia. ${ }^{12-15}$ The incidence of injury in these cases approached $10 \%$ for either extradural or intradural approaches. Traction on the petrosal nerve was believed by some to be the most common cause of the facial palsy. ${ }^{12}$ Gardner et $\mathrm{al}^{16}$ reported their experience of 26 cases with resection of the greater superficial petrosal nerve for headache. Lacrimation returned within two to four months in six cases but remained decreased in most. In addition to an absence of lacrimation, patients occasionally indicated that the nostril felt drier. In this regard, it is interesting to note that our patient experienced a similar outcome but that she regarded this as favorable since she had been troubled by chronic nasal congestion and drainage from the same nostril preoperatively. Seven instances of facial paralysis were reported and attributed to traction. Resection of the geniculate ganglion with or without section of the intermediate nerve for the treatment of primary otalgia resulted in xerophthalmia in virtually all cases. ${ }^{17} \mathrm{~A}$ transient facial paresis was reported in two of 18 patients undergoing the procedure. The sequelae expected of facial nerve injury from Bell's palsy including synkinesis, crocodile tears syndrome, facial spasm, contracture and tinnitus during facial motion ${ }^{18}$ were not seen in our case. Since no facial paresis was evident, one must speculate that a more focal injury isolated to the greater superficial petrosal nerve must have been at fault. Thermal injury through electrocautery of the dura in the vicinity of the petrosal nerve seems most plausible. ${ }^{9,15}$ Rhoton et $\mathrm{al}^{19}$ identified $15 \%$ of temporal bones examined postmortem to be deficient over all or part of the geniculate ganglion and genu of the facial nerve where the petrosal nerve passes into the cranial cavity.

In conclusion, this isolated disturbance of the greater superficial petrosal nerve in the absence of associated injury of the facial nerve proper resulted in the rather unique presentation of xerophthalmia following temporal lobectomy. The presence of facial sensory loss in the maxillary division of the trigeminal nerve is believed to represent an associated disturbance of trigeminal fibers in the same vicinity on the lateral surface of the petrous temporal apex. The findings attest to the vulnerability of neural elements to probable thermal injury transdurally. An historical precedent is partially established from experience with subtemporal rhizotomy in which closely approximated facial neural elements were injured in the course of trigeminal root section. Finally, this report adds to the detailed literature addressing postoperative outcomes in cases of basal and medial resection of the temporal lobe as for cases of epilepsy.

\section{REFERENCES}

1. Crandall PH. Postoperative management and criteria for evaluation. In: Purpura DP, Penry JK, Walter RD, eds. Advances in Neurology. Vol 8. Neurosurgical management of the epilepsies. New York: Raven Press, 1975: 265-279.

2. Falconer MA, Serafetinides EA. A follow-up study of surgery in temporal lobe epilepsy. J Neurol Neurosurg Psychiatry 1963; 26: 154-165.

3. Pilcher WH, Roberts DW, Flanigin HF, et al. Complications of epilepsy surgery. In: Engel J Jr, ed. Surgical Treatment of the Epilepsies. 2nd Ed. New York: Raven Press, 1993: 565-581.

4. Van Buren JM. Complications of surgical procedures in the diagnosis and treatment of epilepsy. In: Engel J Jr, ed. Surgical Treatment of the Epilepsies. New York: Raven Press, 1987: 465475.

5. Awad IA, Chelune GJ. Outcome and complications. In: Wyllie E, ed. The Treatment of Epilepsy: Principles and Practice. Philadelphia: Lea \& Febiger, 1993: 1084-1091.

6. Cahan LD, Sutherling W, McCullough MA, et al. Review of the 20year UCLA experience with surgery for epilepsy. Cleve Clin Q 1984; 51: 313-318.

7. Engel J Jr, Crandall PH, Rausch R. The partial epilepsies. In: Rosenberg RN, ed. The Clinical Neurosciences. New York: Churchill Livingstone, 1983: 1349-1380.

8. Jacobson DM, Warner JJ, Ruggles KH. Transient trochlear nerve palsy following anterior temporal lobectomy for epilepsy. Neurology 1995; 45: 1465-1468.

9. Anderson J, Awad IA, Hahn JF. Delayed facial nerve palsy after temporal lobectomy for epilepsy: report of four cases and discussion of possible mechanisms. Neurosurgery 1991; 28: 453456.

10. Goldring S, Edwards I, Harding GW, Bernardo KL. Results of anterior temporal lobectomy that spares the amygdala in patients with complex partial seizures. J Neurosurg 1992; 77: 185-193.

11. Foley JO, DuBois F. An experimental study of the facial nerve. J Comp Neurol 1943; 79: 79-105.

12. Morello G, Bianchi M, Migliavacca F. Combined extra-intradural temporal rhizotomy for the treatment of trigeminal neuralgia. Results in 409 patients. J Neurosurg 1971; 34: 372-379.

13. Peet MM, Schneider RC. Trigeminal neuralgia. A review of six hundred and eighty-nine cases with a follow-up study on sixtyfive per cent of the group. J Neurosurg 1952; 9: 367-377.

14. Stookey B, Ransohoff J. Trigeminal Neuralgia: Its History and Treatment. Springfield, IL: Charles C. Thomas, 1959.

15. Wilkins RH. The treatment of trigeminal neuralgia by section of the posterior sensory fibers using the transdural temporal approach. J Neurosurg 1966; 25: 370-373.

16. Gardner WJ, Stowell A, Dutlinger R. Resection of the greater superficial petrosal nerve in the treatment of unilateral headache. J Neurosurg 1947; 4: 105-114.

17. Rupa V, Saunders RL, Weider DJ. Geniculate neuralgia: the surgical management of primary otalgia. J Neurosurg 1991; 75: 505-511.

18. Yamamoto E, Nishimura H, Hirono Y. Occurrence of sequelae in Bell's palsy. Acta Otolaryngol Suppl (Stockh) 1988; 446: 93-96.

19. Rhoton AL Jr, Pulec JL, Hall GM, Boyd AS Jr. Absence of bone over the geniculate ganglion. J Neurosurg 1968; 28: 48-53. 